\title{
Concurrent Use of Capecitabine with Adjuvant Radiotherapy in the Treatment of Patients with Breast Cancer
}

Shehata $\mathrm{S}^{1}$, Abbas $\mathrm{H}^{2}$, Mona M Sayed ${ }^{2}$, Hanaan $\mathrm{AEltyb}^{3}$, Ayatallah A Youssief ${ }^{2}$

${ }^{1}$ Department of Clinical Oncology and Nuclear Medicine, Faculty of Medicine, Assiut University

${ }^{2}$ Department of Radiotherapy and Nuclear Medicine, South Egypt Cancer Institute,Assiut University ${ }^{3}$ Department of Medical Oncology, South Egypt Cancer Institute, Assiut University

Correspondence should be addressed to Ayatallah Ali Youssef Mohammed, Department of Radiotherapy and Nuclear Medicine, South Egypt Cancer Institute, El-Methak St., Assiut , Egypt, dr.ayaelderwy@ yahoo.com Authors Information:

Shehata $\mathrm{S}$

Full Name: Prof. Samir Shehata Mohamed Eid

Institutional Address: Professor of Clinical Oncology and Nuclear Medicine, Faculty of Medicine, Assiut

University.

E.mail Address: $\underline{\text { samir@ } @ \text { aun.edu.eg }}$

\section{Abbas H}

Full Name: Prof. Hamza Abbas Hamza Mohammed

Institutional Address: Professor of Radiotherapy and Nuclear Medicine, South Egypt Cancer Institute, Assiut University

E.mail Address: Hamza@aun.edu.eg

\section{Mona M Sayed}

Full Name: Dr. Mona Mahmoud Sayed Ahmed

Institutional Address: Assistant professor of Radiotherapy and Nuclear Medicine, South Egypt Cancer Institute, Assiut University

E.mail Address:mona25jan2011@yahoo.com

\section{Hanaan A Eltyb}

Full Name: Hanaan Ahmed Mohammed Ahmed Eltyb

Institutional Address: Lecturer of Medical Oncology, South Egypt Cancer Institute, Assiut University.

e.mail Address:hanan_eltybe@yahoo.com

\section{AyatallahA Youssief}

Full Name: Ayatallah AliYoussief Mohammed

Institutional Address: Assistant Lecturer of Radiotherapy and Nuclear Medicine, South Egypt Cancer Institute,

Assiut University

E.mail Address:dr.ayaelderwy@yahoo.com 


\section{Abstract \\ Background and objectives:}

Patients with breast cancer have high risk of loco regional and/or distant failure. The loco regional failure rate depending mainly on the disease stage and the adjuvant treatment. Prospective randomized clinical trials have shown promising results with hypo-fractionated schedules for whole breast irradiation. Concurrent chemo radiotherapy is the standard for many solid tumors; it is promising to be investigated in breast cancer. In this study, our aim is to evaluate the toxicity, feasibility, and efficacy of concurrent capecitabine with adjuvant radiotherapy in breast cancer.

Patients and methods: Data of 97 patients with stage II and III breast cancer after surgery and adjuvant chemotherapy, randomized into two groups, group A: 47 patients received concurrent chemoradiation and group B : 50 patients received radiotherapy alone. Patients were assessed for treatment toxicity and local recurrence.

Results: The incidence of acute and late toxicities was comparable in both treatment groups without grade III/IV early toxicity; only a mild increase in gastrointestinal side effects was observed with capecitabine. Most of the late radiation adverse effects were grade I/II. Regarding efficacy, the concurrent capecitabine arm had better disease control locally $(\mathrm{P}$ value $=0.01)$. and better disease free survival $(\mathrm{DFS})(\mathrm{P}$ value $=$ $0.048)$.

Conclusion: Concurrent capecitabine with adjuvant hypofractionated radiotherapy is highly feasible, safe, and effective.

Keywords:breast cancer, concurrent capecitabine, hypofractionation, adjuvant radiotherapy.

\section{Background}

Breast cancer is the most frequency diagnosed cancer in women worldwide and is the leading cause of cancer related death in woman [1].

Adjuvant radiotherapy is indicated for patients who undergo breast-conserving surgery (BCS). For patients who underwent modified radical mastectomy, there are also many studies demonstrated that post mastectomy radiotherapy (PMRT) reduced loco regional recurrence (LR) as well as improved DFS and overall survival (OS)[2, 3, 4].

Prospective randomized clinical trials have shown promising results with hypo fractionated schedules for whole breast irradiation in each of these studies, the goal was to deliver a hypo fractionated dose schedule that is biologically equivalent to conventional radiation fractionation dose of $50 \mathrm{~Gy}$ in 25 fractions / 5 fractions per week. With 5-10 year follow up of these studies, there have been similar results in breast local control between the hypo fractionated and standard fractionated arms [5].

Concurrent chemo radiotherapy will continue to gain importance in the treatment of a variety of malignancies because of the biological synergy effect that can increase the efficacy of the treatment and improve the therapeutic index [6].

Limited published data exist for chemo radiotherapy in local advanced breast cancer, one of the most notable are fluoropyrimidines [7].The most common reported of radiation therapy concurrent with radio sensitizing chemotherapy is in metastatic disease, in inoperable or inflammatory breast cancer patients who progress on first line anthracyclinebased chemotherapy [8, 9].

Radiation has been shown to increase the tumor enzyme levels preferentially, improving the likelihood of capecitabine mediated radio sensitizing and therefore increasing the therapeutic benefit[10].

\section{Patients and Methods}

A prospective study was conducted on 97 patients with stage II and III breast cancer pathologically confirmed infiltrating duct carcinoma, node-positive, invasive breast cancer after surgery and adjuvant chemotherapy, randomized into 2 groups, group A: 47 patients received concurrent chemoradiation and group B: 50 patients received radiotherapy alone from October 2016 to September2018 at Radiotherapy department, South Egypt Cancer 
Institute, Assiut University. The median follow up period was 28 months.

\section{Inclusion criteria}

Female patients, aged $\geq 18$ years , with Eastern Cooperative Oncology Group(ECOG) performance status of $\leq 2$, histologically confirmed infiltrating duct carcinoma of the breast, Patient who underwent modified radical mastectomy with the following criteria: T3 or T4 primary tumor, one or more involved axillary lymph nodes, after breast conservative surgery, patient candidate for radiotherapy, hormone receptor state not specified, written informed consent.

\section{Exclusion Criteria}

Pregnancy, lactation, contraindication to radiotherapy such as previous irradiation or connective tissue disease of the skin and prior treatment with capecitabine.

\section{Pretreatment evaluation}

History and physical examination and baseline investigations were performed; chest radiograph, and pelvi-abdomenal ultrasound, the left ventricular ejection fraction (LVEF should be $\geq 55 \%$ ), bilateral arm circumference measurement, liver and kidney function, BMI, and complete blood count were performed

\section{Study design}

The patients were divided into two arms. The first arm received radiotherapy $4240 \mathrm{CGy}$ in 16 fractions, $2.65 \mathrm{~Gy} /$ fraction, 5 fractions weekly over 3 weeks. The second arm received the same radiotherapy schedule with concurrent capcitabine $825 \mathrm{mg} / \mathrm{m}^{2}$ every twelve hours on radiotherapy days, with boost after breast conservative surgery 14 Gy to lumpectomy area in both arms given using photon beam and 3D treatment planning.

\section{Radiotherapy technique}

Patients lied in the supine position on the wing wedged board with ipsilateral arm raised to degree that allows treatment fields to be easily applicate. Radiopaque wires and markers were used to locate breast tissue and visible surgical scar. Three tattoos were made on the thoracic skin to enable patient repositioning during the treatment. CT simulation scan was conducted from the cricoid to the upper abdomen with both lungs included. Treatment plans for the whole breast were generated by using two opposed tangential beams. Beam weighting, gantry angles, wedges and beam energies were determined to achieve optimal does. The lungs and the heart were the important organ at risk (OAR). Supraclavicular field in node positive, if more than or equal one positive lymph node.

Toxicities were assessed according to Common Terminology Criteria for Adverse Event v4.03 (CTCAE) [11], and the Late Effects Normal Tissue task force Subjective, Objective, Management, and Analytic breast scoring system [12].After patients finished radiation therapy, at every visit, patients were assessed for treatment related toxicity and tumor recurrence [13].

\section{Statistical analysis}

Data was represented as numbers, percentages, means or median. All analysis was conducted using SPSS software version 23. Univariate factors were analyzed using the chi-square test for categorical variables, difference was considered statistically significant at $\mathrm{P}<0.05$, the disease free survival was calculated according to Kaplan Meier method and was compared with the log-rank test.

\section{Results}

A total of 97 patients with stage II and III breast cancer after surgery and adjuvant chemotherapy, 47 patients received concurrent chemoradiation and the other 50 patients received radiotherapy alone.

The mean age of the patients who received concurrent chemoradiation was $51.15 \pm 12.8$ years with a range of 28 to 77 years. Twenty four (51.1\%) women were less than 50 years old. Performance state was one and two in $41(87.2 \%)$ and $6(12.8 \%)$ women respectively in such women as shown in table 1.

While in women who received radiotherapy alone, mean age was $50.70 \pm 12.8$ years with a range of 35 to 75 years. Twenty eight $(56 \%)$ women were less than 50 years old. Performance state was one and two in $46(92 \%)$ and $4(8 \%)$ women respectively in such women as shown in table 1 .

Tumor characteristics in the studied patients are shown at table 1 . Twenty $(42.6 \%)$ and twenty seven (54\%) of patients in chemoradiation group and radiotherapy group respectively had right side breast cancer while the other patients had left side breast cancer(table 1).

Majority of patients (83\% in case of chemoradiation group and $84 \%$ in case of radiotherapy group) had tumor grade 2. Also, majority of patients $(59.6 \%$ in case of chemoradiation group and $66 \%$ in case of radiotherapy group) had T2 tumor stage. Twenty six $(55.3 \%), 10(21.3 \%)$ and $11(23.4 \%)$ patients who 
received chemoradiation had nodal stage N1, N2 and N3 respectively while $31(62 \%), 9(18 \%)$ and $10(20 \%)$ patients who received radiotherapy had nodal stage N1, N2 and N3 respectively (table 1).

Table 1: patient and tumor characteristics

\begin{tabular}{|c|c|c|c|}
\hline & $\begin{array}{c}\text { Chemoradiation }(n= \\
47)\end{array}$ & Radiotherapy $(\mathrm{n}=\mathbf{5 0})$ & $\begin{array}{l}P \\
\text { value }\end{array}$ \\
\hline Age (years) & & & 0.38 \\
\hline Mean (SD) & $51.15(12.8)$ & $50.7(8.64)$ & \\
\hline Range & 28-77 & $35-75$ & \\
\hline$<50$ year & $24(51.1 \%)$ & $28(56 \%)$ & \\
\hline$>50$ year & $23(48.9 \%)$ & $22(44 \%)$ & \\
\hline Performance state & & & 0.33 \\
\hline 1 & $41(87.2 \%)$ & $46(92 \%)$ & \\
\hline 2 & $6(12.8 \%)$ & $4(8 \%)$ & \\
\hline Laterality & & & 0.17 \\
\hline Right side & $20(42.6 \%)$ & $27(54 \%)$ & \\
\hline Left side & $27(57.4 \%)$ & $23(46 \%)$ & \\
\hline Tumor grade & & & 0.87 \\
\hline Grade 1 & $4(8.5 \%)$ & $3(6 \%)$ & \\
\hline Grade 2 & $39(83 \%)$ & $42(84 \%)$ & \\
\hline Grade 3 & $4(8.5 \%)$ & $5(10 \%)$ & \\
\hline Tumor stage & & & 0.46 \\
\hline T1 & $4(8.5 \%)$ & $7(14 \%)$ & \\
\hline $\mathbf{T} 2$ & $28(59.6 \%)$ & $33(66 \%)$ & \\
\hline T3 & $12(25.5 \%)$ & $9(18 \%)$ & \\
\hline T4 & $3(6.4 \%)$ & $1(2 \%)$ & \\
\hline Nodal stage & & & 0.58 \\
\hline N1 & $26(55.3 \%)$ & $31(62 \%)$ & \\
\hline $\mathbf{N 2}$ & $10(21.3 \%)$ & $9(18 \%)$ & \\
\hline N3 & $11(23.4 \%)$ & $10(20 \%)$ & \\
\hline TMN staging & & & 0.09 \\
\hline II & $24(51.1 \%)$ & $33(66 \%)$ & \\
\hline III & $23(48.9 \%)$ & $17(34 \%)$ & \\
\hline $\begin{array}{l}\text { Positive estrogen and progesterone } \\
\text { receptor }\end{array}$ & $40(85.1 \%)$ & $39(78 \%)$ & 0.26 \\
\hline Positive progesterone receptor & $34(72.3 \%)$ & $36(72 \%)$ & 0.57 \\
\hline Positive estrogen receptor & $35(74.5 \%)$ & $37(74 \%)$ & 0.57 \\
\hline Positive Her 2 expression & $6(12.8 \%)$ & $4(8 \%)$ & 0.43 \\
\hline
\end{tabular}

Data was expressed in form of mean (SD), range and frequency (percentage). $P$ value was significant if $<0.05$ 
Regarding stage, $24(51.1 \%)$ of chemoradiation group and $33(66 \%)$ of radiotherapy group had stage II tumor while $23(48.9 \%)$ of chemoradiation group and 17 (34\%) of radiotherapy group had stage III tumor. Positive hormonal state presented in $40(85.1 \%)$ of patients in chemoradiation group and $39(78 \%)$ of patients in radiotherapy group (table 1).

Positive progesterone and positive estrogen receptor presented in $34(72.3 \%)$ and 35 (74.5\%) patients of chemoradiation group respectively and in $36(72 \%)$, and $37(74 \%)$ patients of radiotherapy group respectively. Six patients $(12.8 \%)$ of chemoradiation group and $4(8 \%)$ patients of radiation group had Her 2 overexpression (table 1).

G1 and G2 dermatitis developed only in 7 (14.9\%) and $3(6.4 \%)$ patients from chemoradiation group and 8 (16\%) and $4(8 \%)$ patients of radiotherapy group.

Acute pneumonitis grade 1 occurred in three patients from each group. It was noticed that cardiac toxicity and anemia occurred only with the chemoradiation group only where one patient developed G1 cardiac toxicity and two patients developed G1 anemia.

Two patients in chemoradiation group developed diarrhea grade 1 but none of those patients in radiotherapy group developed diarrhea. Three $(6.4 \%)$ and $2(4.3 \%)$ patients in chemoradiation group suffered from gastritis grade 1 and 2 respectively while only $2(4 \%)$ patients in radiotherapy group suffered from gastritis grade 1(table 2).

\section{Table 2: Early treatment-related toxicity in both} treatment groups

\begin{tabular}{|c|c|c|c|}
\hline $\begin{array}{r}\begin{array}{r}\text { Treatment related } \\
\text { toxicicty }\end{array} \\
\end{array}$ & $\begin{array}{r}\begin{array}{r}\text { Chemoradtion } \\
(\mathrm{n}=47)\end{array} \\
\end{array}$ & $\begin{array}{r}\text { Radiotherapy } \\
(\mathbf{n}=\mathbf{5 0})\end{array}$ & P value \\
\hline $\begin{array}{ll}\text { Skin } & \\
& \text { G0 } \\
& \text { G1 } \\
& \text { G2 }\end{array}$ & $\begin{array}{l}37(78.7 \%) \\
7(14.9 \%) \\
3(6.4 \%)\end{array}$ & $\begin{array}{l}38(76 \%) \\
8(16 \%) \\
4(8 \%)\end{array}$ & 0.93 \\
\hline $\begin{array}{l}\text { Pneumonitis } \\
\text { G0 } \\
\text { G1 }\end{array}$ & $\begin{array}{l}44(93.6 \%) \\
3(6.4 \%)\end{array}$ & $\begin{array}{l}47(94 \%) \\
3(6 \%)\end{array}$ & 0.63 \\
\hline $\begin{array}{l}\text { Anemia } \\
\text { G0 } \\
\text { G1 }\end{array}$ & $\begin{array}{l}45(95.7 \%) \\
2(4.3 \%)\end{array}$ & $\begin{array}{c}50(100 \%) \\
0\end{array}$ & 0.32 \\
\hline $\begin{array}{l}\text { Gastritis } \\
\text { G1 } \\
\text { G2 }\end{array}$ & $\begin{array}{l}3(6.4 \%) \\
2(4.3 \%)\end{array}$ & $\begin{array}{c}2(4 \%) \\
0\end{array}$ & 0.28 \\
\hline $\begin{array}{l}\text { Diarrhea } \\
\text { G1 }\end{array}$ & $2(4.3 \%)$ & 0 & 0.23 \\
\hline $\begin{array}{l}\text { Nausea } \\
\text { G1 } \\
\text { G2 }\end{array}$ & $\begin{array}{l}3(6.4 \%) \\
3(6.4 \%)\end{array}$ & $\begin{array}{c}1(2 \%) \\
0\end{array}$ & 0.09 \\
\hline $\begin{array}{l}\text { Vomiting } \\
\text { G1 } \\
\text { G2 }\end{array}$ & $4(8.5 \%)$ & $\begin{array}{c}1(2 \%) \\
0\end{array}$ & 0.09 \\
\hline $\begin{array}{l}\text { Cardiac toxicity } \\
\text { G0 } \\
\text { G1 }\end{array}$ & $\begin{array}{l}46(97.9 \%) \\
1(2.1 \%)\end{array}$ & $\begin{array}{r}50(100 \%) \\
0\end{array}$ & 0.55 \\
\hline
\end{tabular}


Nausea grades I and II occurred in $3(6.4 \%)$ patients and vomiting grade 1 and II occurred in $4(8.5 \%)$ and 1 (2.1\%) patients of chemoradiation groups while nausea and vomiting grade 1 occurred in one patient $(2 \%)$ in radiotherapy group as shown in table 2 .

Chronic pneumonitis occurred in only one patient $(2 \%)$ in radiotherapy group. Late skin and subcutaneous tissue toxicities, skin hyperpigmentation, subcutaneous tissues fibrosis/fat necrosis and lymphedema were comparable in both treatment groups, and most of them were GI and GII with no significant difference as shown in table 3.

Table 3: Late treatment-related toxicity in both treatment groups

\begin{tabular}{|c|c|c|c|}
\hline $\begin{array}{l}\text { Treatment related } \\
\text { Toxicities }\end{array}$ & $\begin{array}{r}\text { Chemoradiation } \\
(\mathrm{n}=47)\end{array}$ & $\begin{array}{r}\begin{array}{r}\text { Radiotherapy } \\
(\mathbf{n}=\mathbf{5 0})\end{array} \\
\end{array}$ & $P$ value \\
\hline Pneumonia & & & \\
\hline G0 & $47(100 \%)$ & $49(76 \%)$ & 0.5 \\
\hline G1 & 0 & $1(2 \%)$ & \\
\hline Hyperpigmentaion & & & 0.52 \\
\hline G0 & $35(74.5 \%)$ & $38(76 \%)$ & \\
\hline G1 & $12(25.5 \%)$ & $12(24 \%)$ & \\
\hline Fibrosis & & & 0.46 \\
\hline Go & $42(89.4 \%)$ & $46(92 \%)$ & \\
\hline G1 & $5(10.6 \%)$ & $4(8 \%)$ & \\
\hline Telangiectasia & & & 0.60 \\
\hline G0 & $43(91.5 \%)$ & $46(92 \%)$ & \\
\hline G1 & $4(8.5 \%)$ & $4(8 \%)$ & \\
\hline Lymphedema & & & 0.78 \\
\hline G0 & $29(61.7 \%)$ & $34(68 \%)$ & \\
\hline G1 & $12(25.5 \%)$ & $10(20 \%)$ & \\
\hline G2 & $6(12.8 \%)$ & $6(12 \%)$ & \\
\hline
\end{tabular}

Table 4: Frequency of recurrence in the current study

\begin{tabular}{lccc}
\hline & Chemoradiation $(\mathbf{n}=$ & Radiotherapy $(\mathbf{n}=$ & $\mathbf{P}$ \\
& $\mathbf{4 7})$ & $\mathbf{5 0})$ & value \\
\hline Local recurrence & $2(4.3 \%)$ & $7(14 \%)$ & 0.01 \\
Distant metastasis & $1(2.1 \%)$ & $3(6 \%)$ & 0.65 \\
\hline
\end{tabular}

It was noticed that the frequency of local recurrence was significantly higher $(14 \%)$ in those patients of radiotherapy alone group in comparison to those patients of chemoradiation $(4.3 \% ; \mathrm{P}=0.01)$. Also, distant metastasis was higher in radiotherapy alone group but was of no significant value $(2.1 \%$ versus $6 \% ; \mathrm{P}=0.65)$. As shown in table 4 .
After median follow up 23 months in both groups, the two years disease free survival was $91.9 \%$ for chemo radiation group and $72.5 \%$ for radiotherapy group. There was significant difference between both groups by the use of log-rank test ( $p$ value $=0.048$ ). It was noticed that TNM was the only prognostic factor for disease free survival $(\mathrm{OR}=2.13$, $95 \% \mathrm{CI}=2.33-3.21 ; \mathrm{P}=0.00)$ as shown in table 5 and figure 1. 
Table 5: Disease Free Survival in the Current Study

\begin{tabular}{lccc}
\hline Variables & Odd's ratio & 95\% confidence interval & P value \\
\hline Age & 1.99 & $1.47-1.34$ & 0.23 \\
\hline Side of tumor & 1.14 & $2.09-2 . .43$ & 0.14 \\
Tumor stage & 1.33 & $1.09-1.76$ & 0.56 \\
TNM stage & 2.13 & $2.33-3.21$ & 0.00 \\
Tumor grade & 0.45 & $0.99-1.25$ & 0.21 \\
Type of surgery & 0.31 & $1.83-2.01$ & 0.89 \\
Previous chemotherapy & 0.61 & $0.52-0.57$ & 0.19 \\
Positive hormonal state & 0.74 & $1.21-1.51$ & 0.22 \\
(estrogen and progesterone) & & & 0.37 \\
\hline Positive estrogen receptor & 1.34 & $1.23-1.55$ & 0.98 \\
\hline $\begin{array}{l}\text { Positive progesterone } \\
\text { receptor }\end{array}$ & 2.01 & $0.99-1.01$ & \\
\hline
\end{tabular}

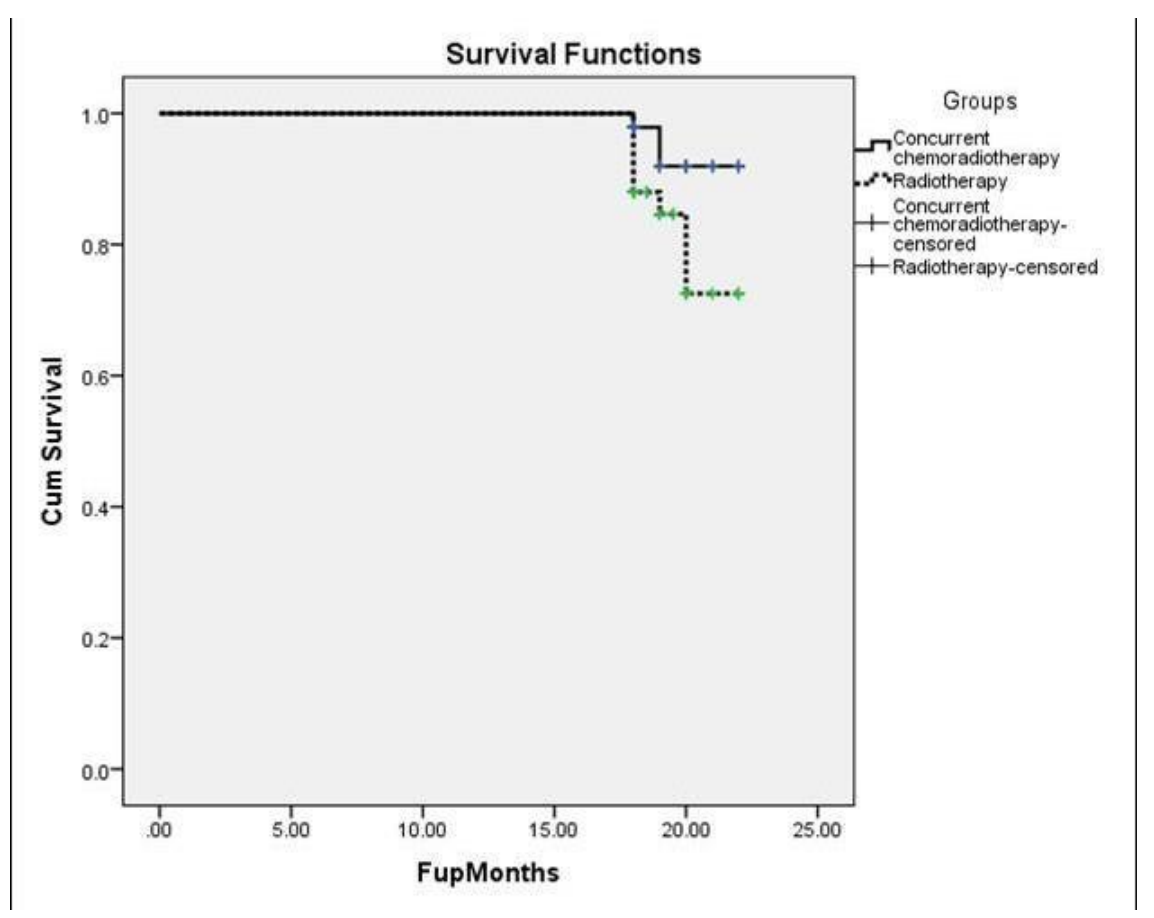

Figure 4:DFS of the current study 


\section{Discussion}

A considerable number of studies have been accomplished on determination the efficacy and safety of concurrent capecitabine with adjuvant radiotherapy in breast cancer, the most common reported is in metastatic disease, inoperable or inflammatory breast cancer patients who progress on first line anthracycline-based chemotherapy [8,9]. This phase II study was performed to ascertain the safety and feasibility of capecitabine concurrent with adjuvant radiation therapy in breast cancer.

In our study the mean age of chemoradiation group was 51.15 years with age ranged from 28 to 77 Years and $51.5 \%$ of patients were $<50$ years of age, which is comparable with the mean age 52 years that was reported by Garwood et al. [14].

In our study, after median follow up 23 months in both groups, the two years disease free survival was $91.9 \%$ for chemoradiation group and $72.5 \%$ for radiotherapy group. While the 5 years DFS that was reported by Garwood et al. a single-arm phase II study with similar capecitabine daily dose, but with 50 Gy in 25 fraction was62.5\% , longer follow up may prove similar results [14].

It was noticed that frequency of local recurrence was significantly higher (14\%) in those patients of radiotherapy group in comparison to those patients of chemo- radiation $(4.3 \% ; \mathrm{p}=0.01)$. Our results were in consistent with that reported in Garwood et al.as the 1-year infield loco regional recurrence(LRR)was $4 \%$ [14].

In our study, there was no GIII/IV radiation dermatitis; both arms were comparable in the incidence of GI/II. In group B, GI skin reaction was observed in seven (14.9\%) patients and GII in two (6.4\%) patients, whereas in group A, GI was observed in $(16 \%)$ patients and GII in $(8 \%)$ patients. Higher incidence of radiation dermatitis was reported by Garwood et al. with GI 32\%, GII 10\%, and GIII $14 \%$; this difference could be due to inclusion of more patients with breast-conserved surgery, with whole breast irradiation, which increases the risk of radio dermatitis and also a higher total dose (boost) with a median radiation dose of $6040 \mathrm{cGy}$ compared with $4240 \mathrm{cGy}$ in our study[14]. The low rates of the skin toxicity in our study may be due to the very small percentage of patients with breast conserving surgery $(10 \%)$ in the whole study population. In contrast to our results, Shahid et al. reported in their hypo fractionated PMRT study a higher incidence of chest wall radiation skin reaction with $40 \mathrm{~Gy}$ in the 15-fraction radiotherapy arm; radiation dermatitis was as follows: GI $62 \%$, GII $24 \%$, GIII $11 \%$, and GIV $3 \%$; this high incidence of radio dermatitis could be explained by the use of a cobalt 60 radiotherapy treatment machine and the addition of posterior axillary boost in some patients [15].

Both treatment groups were comparable in the incidence and the grading of different late radiation effects and comparable to results reported by Alshimaa et al. except lymphedema which is more frequent in our study, extensive lymphadenectomy (more than 20 lymph nodes) and higher total radiation does may be our explanation. The most common type of late toxicity was hyperpigmentation: all were GI (24\%) in group A $(25.5 \%)$ in group B, while Alshimaa et al.GI and GII total (27\%)[16].Chest wall fibrosis GI reported in (8\%) in group A and (10.5\%) in group B and telangiectasia also were GI in both treatment groups $(8 \%)$ and $(8.5 \%)$ in group A and group B respectively, while in Alshimaa et al. chest wall fibrosis and telangiectasia were observed in total $11 \%$ and $7 \%$ respectively and it was comparable in both groups. Eldeeb et al. published 11-year follow-up results of a PMRT hypo fractionated trial, with the $40 \mathrm{~Gy}$ in 15 fractions over three weeks. Hyperpigmentation was reported in $20 \%$, fibrosis GII/III was noticed in $37 \%$, and telangiectasia GII/III was seen in only $7 \%$ of the cases; these higher rates compared with ours may be due to the longer follow-up [17]. In our study, in group B, GI lymphedema was observed in seven $(22.9 \%)$ patients and GII in two (12.5\%) patients, whereas in group A, GI was observed in $(25.5 \%)$ patients and GII in (12.8\%) patients. While in Alshimaa et al. lymphedema was detected in total $10 \%$ of the studied patients; most of the cases were grade I and grade II[16]. Higher incidence of GI and GII lymphedema $43 \%$ reported by Uma Goyal et al. who investigated capecitabine $1000 \mathrm{mg}$ p.o. twice a day (b.i.d.) for 2 cycles during RT and 4 cycles of $1000-1500 \mathrm{mg}$ p.o.b.i.d. after RT completed and RT was 45-50.4Gy in 1.8-2Gy daily fractions in high risk patients after neoadjuvant chemotherapy and surgery. Higher total capecitabine dose may explain that difference[18].

The addition of capecitabine to radiotherapy was not associated with an increased incidence of lung toxicity as there were no cases of radiation induced symptomatic pneumonitis or lung fibrosis, which is similar to Uma Goyal et al. [18]. In this study only three patients (6.4\%) cases showed GI (asymptomatic) radiation pneumonitis; three patients in each group; both patients had received a supraclavicular field irradiation. 
The incidence of GI nausea was only $(6.4 \%)$, nausea and vomiting was $(8.5 \%)$, GII nausea was only (6.4) $\%$, nausea and vomiting was $(2.1) \%$. Similar to our study, no GIII or IV adverse events were reported in an Egyptian study by Hussein et al. Which included patients with locally advanced breast cancer; the capecitabine dose was similar, but with conventional radiotherapy; the incidence of GI nausea was only $14 \%$, nausea and vomiting was $7 \%$, GII nausea was only $3 \%$, nausea and vomiting was $7 \%$ [19].

In this study hematological toxicity GI anemia was reported in $(4.3 \%)$ similar to results that was reported by Fatma Zakaria et al. who examined the concomitant use of conventional breast irradiation and similar capecitabine dose as a second-line neoadjuvant treatment in locally advanced breast cancer, who were refractory to first line anthracycline based regimens. The incidence of hematologic toxicities was mild: only one patient with GI anemia (3.4\%)[20]. In contrast, Garwood et al. reported a higher incidence of hematological toxicity, but they included GI and GII only, with $8 \%$ GI and $8 \%$ GII; this difference in toxicity might be explained by the ethnic differences, which may result in a difference in the pharmacokinetics and the toxicity of capecitabine between the patients in the Egyptian and the USA populations; this could be further investigated [14].

In our study there was no decrease in LVEF with treatment except in one left sided patient where the LVEF decreased less than $10 \%$ from the base line and the patient was asymptomatic. Also the age of the patient (70 years old) and the known history of hypertension may considered other contributable factors. While no cardiac toxicity reported by Alshimaa et al. In contrast to Garwood et al. who reported one patient with grade 5 (cardiac arrest) possibly related to capecitabine[16, 14].

Similarly, we did not report any cases of hand food syndrome (HFS) in our study in accordance with the study by Hussen et al. [19]. Whereas Garwood et al. reported total $44 \%$ incidence of HFS[14].The mean age of the two studies were comparable: 45 years in study by Hussein et al. and 52 years in the study by Garwood et al. This difference cannot be explained, although the difference in ethnicity might play a role. Also, the short duration of treatment in our study may have a lower probability of occurrence of HFS during treatment, as the onset of incidence of capecitabine HFS was from 11 to 360 days; hence, the longer the duration, the higher the possibility of its incidence

\section{Conclusion}

Generally, the incidence of acute and late toxicities were comparable in both treatment groups with no incidence of grade III/IV early toxicity; only a mild increase in gastrointestinal side effects was observed with capecitabine; however, $96 \%$ of the patients were able to finish their concurrent capecitabine therapy and all patients finished radiotherapy without interruption due to toxicity. Most of the late radiation adverse effects were grade I/II. Regarding efficacy, the concurrent capecitabine arm had better local disease control, and better disease-free survival. Larger studies with longer follow up may prove a difference

\section{Conflict of Interests}

The authors declare that they have no conflict of interests.

\section{References}

1-Siegel RL,MillerKD,JemelA. Cancer Statistics,2017.CA Cancer JClin 2017 ;66:7-30.

2-Van de Steene J, Soete G, Storme G.Adjuvant radiotherapy for breast cancer significantly I improve overall survival. Radiother Oncol 55:263272,2000 .

3-Ragaz J. Jackson SM, Plenderleith IH. .et al. Adjuvant radiotherapy and chemotherapy in node positive premenopausal women with breast cancer. The New England Journal of Medicine 1997; 9-17(5).956-962.

4-Gebski V, Lagleva M, Keech A, et al. Survival effects of post mastectomy adjuvant radiation therapy using biologically equivalent doses: a clinical perspective. J Natl Cancer Inst; 98: 26-38, 2006.

5-Whelan TJ, Pignol JP, Levine MN, et al. Longterm results of Hypo fractionated radiation therapy for breast cancer. N Engl J Med 2010; 362(6):513-520.

6-Pierce LJ. The use of radiotherapy after mastectomy: a review of the literature. J ClinOncol 2005; 23:1706-1717.Peto J and Mack TM. High constant incidence in twins and other relatives of women with breast cancer. Nat Genet 2000; 26:411.

7-Shanta V, Swaminathan R, Rama R, et al, Retrospective analysis of locally advanced non inflammatory breast cancer from Chennai, South India, 1990-1999.Int J Radiatoncol Biol phys.2008 Jan 1, 70(1):51-8. Epub 2007 sep 14. 
8-Genet D, Lejeune C,Bonnier p,et al. Concomitant intensive chemo radiotherapy induction in nonmetastatic inflammatory breast cancer: long term follow up.BrJ Cancer 2007;97:883-887.

9-Woodward WA, Fang P, Arriaga L, et al. A phase 2 study of preoperative capecitabine and concomitant radiation in women with advanced breast cancer. Int $\mathrm{J}$ Radiat Oncol BiolPhys 2017;99:777-783.

10-EreminJ,Cowley G, Walker LG, et al. Women with large $(>/=3 \mathrm{~cm})$ and locally advanced breast cancers 4, (T3, N1, 2, M0) receiving neoadjuvant chemotherapy (NAC: cyclophosphamide, doxorubicin, docetaxel): addition of capecitabine improves 4-year disease free survival. Springerplus. 2015; 4:9.

11-US NCI. Common Terminology Criteria for Adverse Event v4.03 (CTCAE) 2010.

12-[No authors listed]. LENT SOMA scales for all anatomic sites.Int J Radiat Oncol BiolPhys 1995; 31:1049-1091.

13-Kaplan E and Meier P.Non-parametric estimation from incomplete observations. Journal of the American Statistical Association 1958; 53 (282), 457-4.

14-Garwood D, Spangler A, Derose P, et al. A pilot safety and feasibility study of concurrent capecitabine and external beam irradiation in the adjuvant treatment of high risk early breast cancer. Cancer Res 2010; 70: San Antonio Breast Cancer Symposium, December 15, 2010; [Abstract] No: P 4- 11- 08.
15-Shahid A, Athar MA, Asghar S, et al. Post mastectomy adjuvant radiotherapy in breast cancer: a comparison of three hypo fractionated protocols. J Pak Med Assoc 2009; 59:282-287.

16-Alshimaa M Alhanafy, Tarek A Hashem, Mohamed Abu El-Fetouh et al.Safety and feasibility of concurrent capecitabine and hypo fractionated post mastectomy radiotherapy. Menoufia Medical Journal, 28:325-332,2015.

17-Eldeeb H,Awad I and Elhanafy O. Hypo fractionation in post-mastectomy breast cancer patients: seven-year follow-up. Med Oncol 2012; 29:2570-2576.

18-Uma Goyal, Tijana Skrepnik1,Rajayogesh Davuluri1 et al. Concurrent Capecitabine and Radiation Therapy for High-risk Primary Breast Cancer. Oncomedicine 2017; 2:61-65.

19-Hussen FZ, Gamal El-Deen HS, Ghanam A, et al. The outcomes of concomitant radiation therapy plus capecitabine for refractory locally advanced breast cancer patients pre-treated with anthracycline based regimens. J Am Sci 2010; 6: 564-574.

20-Fatma Zakaria Hussein, Hanan Shawky Gamal El-Deen ,Amr Abd- El Aziz Ghanam et al . The Outcomes of Concomitant Radiation Therapy plus Capecitabine for Refractory Locally Advanced Breast Cancer Patients Pre-Treated with Anthracycline Based Regimens. Journal of American Science 2010; 6(12):564-574 